\title{
Peroral intraductal cholangioscopy-guided laser lithotripsy via endoscopic ultrasound-guided hepaticogastrostomy for intrahepatic bile duct lithiasis
}

A 25-year-old man was referred for recurrent cholangitis. At the age of 5 , he had undergone surgery for a Todani Type 1 choledochal cyst, with a Roux-en-Y hepaticojejunostomy reconstruction. He experienced several bouts of cholangitis in 2016. Magnetic resonance cholangiopancreatography (MRCP) showed dilated intrahepatic ducts, with bile duct stones in the right posterior sector and above a stenosis at the hepaticojejunal anastomosis ( $\triangleright$ Video 1 ).

Endoscopic ultrasound-guided hepaticogastrostomy (EUS-HGS) was performed using a curved linear array echoendoscope. Access to the left hepatic ducts was obtained from the proximal gastric cardia using a 19-gauge access needle. The cholangiogram showed a stricture of the anastomosis with stones above it, free-draining left and right anterior ducts, and obstructed right posterior ducts. The needle tract was coagulated before a large fully covered self-expandable metal stent (FCSEMS; 8-cm long, 10 -mm diameter) was inserted into the left hepatic duct. A hydrostatic macrodilation (to $15 \mathrm{~mm}$ in diameter) of the anastomosis was performed ( and stones at the main confluence were pushed downwards into the jejunal limb ( $\vee$ Video 1).

Direct antegrade peroral video cholangioscopy (SpyGlass DS; Boston Scientific) was performed 2 weeks later through the HGS after hydrostatic dilation to $8 \mathrm{~mm}$. Cholangioscopic exploration of the biliary tract confirmed complete stone obstruction of the right posterior biliary tract. Laser lithotripsy was performed (1200 mJ, 4 Hz; Holmium, Auriga) and the stones were completely removed by fragmentation ( $>$ Fig. 2 )

The patient was discharged 24 hours after the procedure. The FCSEMS was removed 2 months later and a double pigtail stent $(10 \mathrm{Fr} \times 15 \mathrm{~cm})$ was left in position passing through the HGS for 12

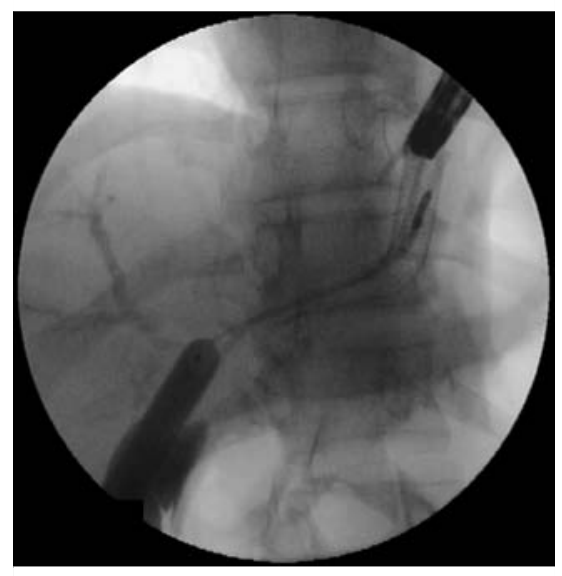

- Fig. 1 Radiographic image showing hydrostatic macrodilation (diameter $15 \mathrm{~mm}$ ) of the hepaticojejunal anastomosis through the hepaticogastrostomy access under fluoroscopic guidance.

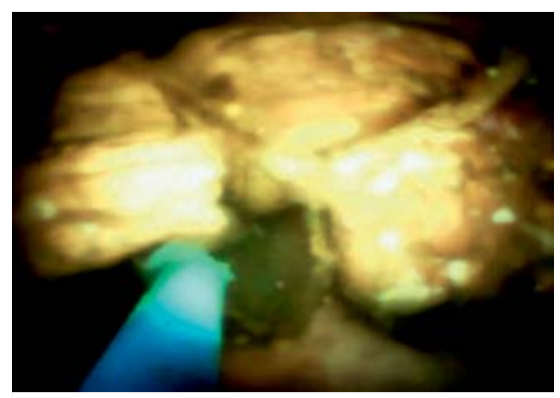

- Fig. 2 View during antegrade peroral video cholangioscopy through the hepaticogastrostomy stent with laser lithotripsy of the stones being performed.

months to maintain the patency of the hepaticogastric anastomosis. After the double pigtail stent had been removed, direct cholangiography using a balloon catheter ( $\mathbf{F i g . 3}$ ) and magnetic resonance imaging ( $\triangleright$ Fig.4) showed the absence of any residual stones and an entirely normal cholangiogram. The patient remained symptom free 1 year after this procedure.

Endoscopy_UCTN_Code_TTT_1AR_2AH

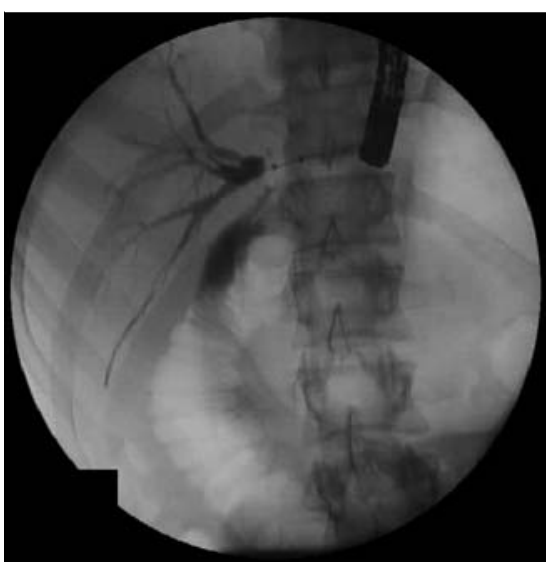

Fig. 3 Image from direct cholangiography using a balloon catheter showing the absence of any residual stones and an entirely normal cholangiogram.

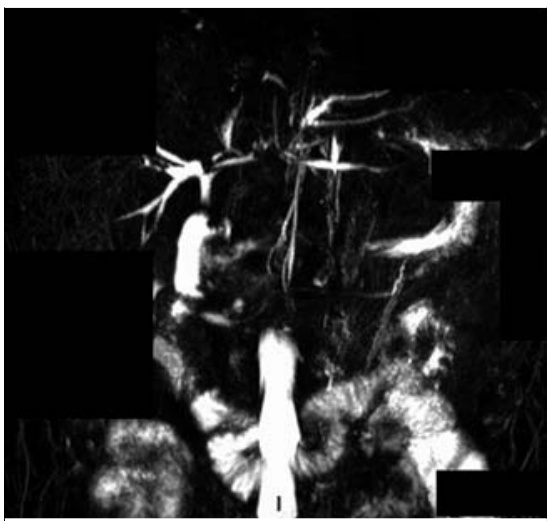

- Fig. 4 Magnetic resonance imaging after the procedure showing the absence of residual stones and no dilatation of the biliary tree.

Competing interests

Frederic Prat declares that he has received lecture fee and has been involved in an adivisory board from Boston Scientifc in the past 3 years. 


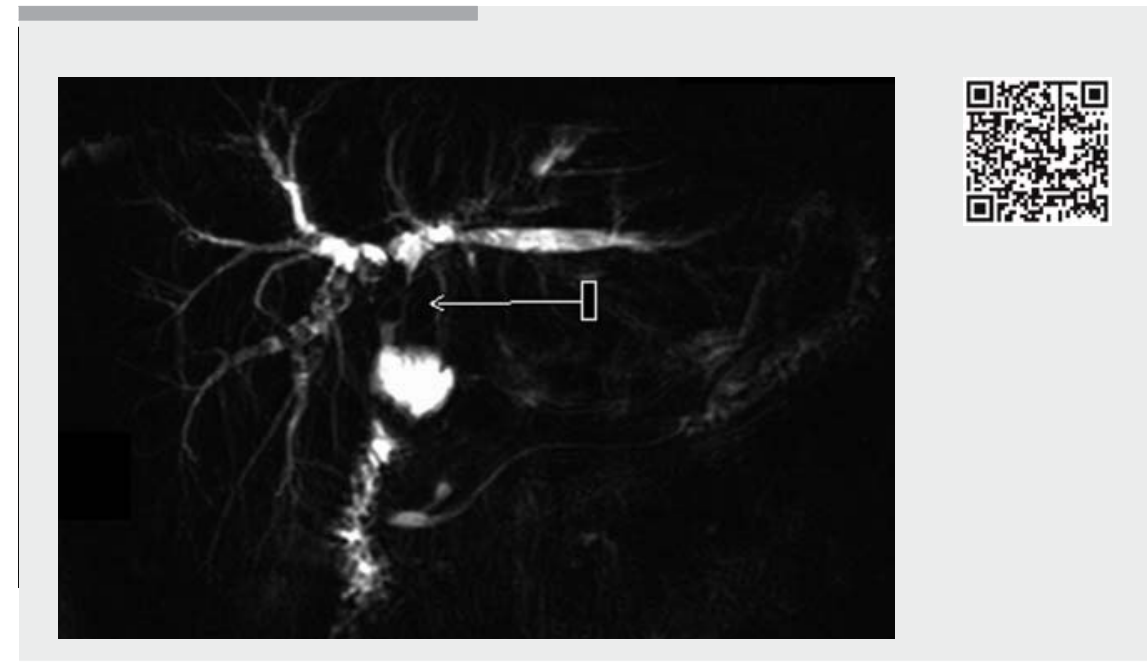

Video 1 Peroral intraductal cholangioscopy-guided laser lithotripsy through an endoscopic ultrasound-guided hepaticogastrostomy route for intrahepatic bile duct lithiasis.

The authors

Adrien Sportes ${ }^{1,2}$, Sarah Leblanc ${ }^{1}$, Benoit Bordacahar ${ }^{1}$, Maximilien Barret ${ }^{1}$, Frederic Prat $^{1}$

1 Gastroenterology Unit, Hôpital Cochin (AP-HP), Paris, France

2 Gastroenterology Unit, Institut Arnault Tzanck, Saint-Laurent-du-Var, France

\section{Bibliography}

DOI https://doi.org/10.1055/a-0866-8986

Published online: 25.3.2019

Endoscopy 2019; 51: E135-E136

(c) Georg Thieme Verlag KG

Stuttgart · New York

ISSN 0013-726X

\section{ENDOSCOPY E-VIDEOS \\ https://eref.thieme.de/e-videos}

口回 Endoscopy E-Videos is a free 茴制: access online section, reporting on interesting cases and new techniques in gastroenterological endoscopy. All papers include a high quality video and all contributions are freely accessible online.

This section has its own submission website at

https://mc.manuscriptcentral.com/e-videos

\section{Frederic Prat, MD PhD}

Gastroenterology Unit, Hôpital Cochin (AP-HP), 27 Rue du Faubourg Saint-Jacques, 75014 Paris, France

Fax: +33-1-58411965

Frederic.prat@aphp.fr 